\title{
Daikenchuto, a traditional Japanese herbal medicine, ameliorates postoperative ileus by anti-inflammatory action through nicotinic acetylcholine receptors
}

\author{
Mari Endo • Masatoshi Hori · Hiroshi Ozaki • \\ Tetsuro Oikawa $\cdot$ Toshihiko Hanawa
}

Received: 12 February 2013/ Accepted: 15 June 2013/Published online: 12 July 2013

(c) The Author(s) 2013. This article is published with open access at Springerlink.com

\begin{abstract}
Background Daikenchuto (DKT), a gastrointestinal prokinetic Japanese herbal medicine, is prescribed for patients with postoperative ileus (POI) and adhesive bowel obstruction following abdominal surgery. Several mechanisms for the amelioration of POI by DKT have been suggested; however, it has remained unclear whether DKT shows anti-inflammatory effects in POI. In the present study, we investigated the effects of DKT in a mouse POI model and attempted to clarify the detailed mechanisms of action. Method Intestinal manipulation (IM) was applied to the distal ileum of mice. DKT was administered orally to the animals 4 times before and after IM. Gastrointestinal transit in vivo, leukocyte infiltration, cytokine mRNA expression and gastrointestinal motility were analyzed. We also investigated the effects of the $\alpha 7 \mathrm{nAChR}$ antagonist methyllycaconitine citrate (MLA) on the DKT-mediated ameliorative action against POI, and we studied the effects of DKT on inflammatory activity in $\alpha 7 n A C h R$ knockout mice.
\end{abstract}

M. Endo · T. Oikawa · T. Hanawa

Department of Clinical Research, Oriental Medicine Research

Center, Kitasato University, 5-9-1 Shirokane, Minato-ku,

Tokyo 108-8642, Japan

e-mail: oikawa-t@insti.kitasato-u.ac.jp

M. Hori $(\square) \cdot$ H. Ozaki

Department of Veterinary Pharmacology, Graduate School

of Agriculture and Life Sciences, The University of Tokyo,

1-1-1 Yayoi, Bunkyo-ku, Tokyo 113-8657, Japan

e-mail: ahori@mail.ecc.u-tokyo.ac.jp

T. Hanawa

Department of Oriental Medicine, Doctoral Program of Medical

Science, Kitasato University Graduate School,

1-15-1 kitasato, Sagamihara-shi, Kanagawa 228-8555, Japan
Results DKT treatment led to recovery of the delayed intestinal transit induced by IM. DKT significantly inhibited the infiltration of neutrophils and CD68-positive macrophages, and inhibited mRNA expressions of TNF- $\alpha$ and MCP-1. MLA significantly reduced the anti-inflammatory action of DKT, and the amelioration of macrophage infiltration by DKT was partially suppressed in $\alpha 7 \mathrm{nAChR}$ knockout mice.

Conclusions In conclusion, in addition to the gastrointestinal prokinetic action, DKT serves as a novel therapeutic agent for POI characterized by its anti-inflammatory potency. The DKT-induced anti-inflammatory activity may be partly mediated by activation of $\alpha 7 \mathrm{nAChR}$.

Keywords Anti-inflammatory action - Daikenchuto · Macrophage - Nicotinic acetylcholine receptor . Postoperative ileus

\begin{tabular}{ll}
\multicolumn{2}{l}{ Abbreviations } \\
POI & Post-operative ileus \\
DKT & Daikenchuto \\
IM & Intestinal manipulation \\
$\alpha 7 \mathrm{nAChR}$ & $\alpha 7$ Nicotinic acetylcholine receptor \\
TNF- $\alpha$ & Tumor necrosis factor alpha
\end{tabular}

\section{Introduction}

Post operative ileus (POI) is a problem that results in treatment delays and increased cost burden of hospitalization among patients undergoing abdominal surgery [1]. Gastrointestinal prokinetic agents, such as metoclopramide [2], cisapride [3] and mosapride [4, 5], provide treatment options for POI. At present, however, they are rarely used 
in clinical settings. Therefore, further elucidation of the pathogenesis of POI and establishment of new options for its treatment are required [6].

Daikenchuto (DKT) is a traditional herbal (Kampo) medicine in Japan, and comprises four medical herbs; zanthoxylum fruit, processed dried ginger, ginseng, and malt sugar. This formula is known for its prokinetic action or clinical efficacy against intestinal obstruction subsequent to laparotomy or radiation therapy [7-11]. In experimental studies, DKT showed preventive effects against POI $[8,12,13]$. It is conceivable that DKT stimulates intestinal motility and accelerates delayed intestinal transit through the cholinergic pathway and activation of $5-\mathrm{HT}_{3} \mathrm{R}$ and $5-\mathrm{HT}_{4} \mathrm{R}$. The main mechanism of contractile action and improvement of gastrointestinal motility mediated by DKT is the release of acetylcholine (ACh) from the cholinergic nerves through $5-\mathrm{HT}_{3} \mathrm{R}$ and $5-\mathrm{HT}_{4} \mathrm{R}$ stimulation [12-14]. This ACh improves delayed intestinal transit and recovers delayed gastric emptying in POI [12-14].

Recent studies have revealed that local inflammation is responsible for prolonging post-operative gastrointestinal motility disorder $[6,15]$. Macrophages and neutrophils play a pivotal role in the induction of post-operative ileus. These inflammatory cells express inducible nitric oxide synthase, which in turn produces nitric oxide, thus inducing gastrointestinal motility disorder [16, 17]. As noted above, gastroprokinetic agents such as $5-\mathrm{HT}_{4} \mathrm{R}$ agonists provide effective therapeutic treatment for POI. We recently found that mosapride citrate exerts anti-inflammatory effects by activating alpha7 nicotinic acetylcholine receptors $(\alpha 7 \mathrm{nAChR})$ on macrophages via released ACh from myenteric plexus, which in turn ameliorates POI [5].

On the other hand, it has been reported that DKT decreases serum $\mathrm{C}$ reactive protein (CRP) levels induced by laparoscopic colorectal resection [18], and increases adrenomedullin (ADM) and calcitonin gene-related peptide (CGRP) levels $[19,20]$. We therefore hypothesized that DKT prevents POI due to its gastroprokinetic activity, as well as it antiinflammatory action via $\alpha 7 \mathrm{nAChR}$ stimulation and other pathways. In the present study, we investigated the efficacy and mechanisms of action of DKT primarily on its antiinflammatory potency, using a mouse POI model. The results indicated that DKT has an anti-inflammatory action, in addition to its prokinetic action, and part of this anti-inflammatory action is mediated through $\alpha 7 \mathrm{nAChR}$ activation.

\section{Materials and methods}

Animals

Male BALB/c mice (Japan SLC, Hamamatsu, Japan) weighing 21-26 g were used. Mice were housed under conditions of constant temperature $\left(23 \pm 2{ }^{\circ} \mathrm{C}\right)$ and humidity $(55 \pm 10 \%)$ with standard rodent chow and water ad libitum, and a 12-h light/dark cycle. All animal experiments were performed according to the "Regulations for the Care and Use of Laboratory Animals in Kitasato University" published by Kitasato University. The Institutional Animal Care and Use Committee for Kitasato University approved the study protocol.

Female and male $\alpha 7 \mathrm{nAChR}$ knock out (KO) mice of C57BL/6J background and weighing 21-23 $\mathrm{g}$ (The Jackson Laboratory, Bar Harbor, ME) were obtained from backcrossing with wild-type (WT; C57BL/6J) strains. Mice were cared for in strict compliance with the "Guide to Animal Use and Care" published by the University of Tokyo. The Institutional Review Board of the Graduate School of Agriculture and Life Science of the University of Tokyo approved the study protocol.

Preparation of Kampo medicines

DKT was blended in the Oriental Medicine Research Center of Kitasato University. Daily human doses $(190 \mathrm{mg} / \mathrm{kg})$ of the crude herbs (ninjin, Ginsen radix 3.0 g; kankyo, Zingiberis Siccatum rhizoma 3.0 g; sansho, Zanthoxylum fructus $2.0 \mathrm{~g}$; and koi, Saccharum Gramorumb $20.0 \mathrm{~g}$ ) in DKT were decocted with $600 \mathrm{ml}$ of distilled water until the filtered decoction was reduced by half. The decocted extract solution was centrifuged at 3,000 rpm for $15 \mathrm{~min}$, and the supernatant was lyophilized. The obtained freeze-dried powder $(9.5 \mathrm{~g})$ was dissolved in distilled water to the appropriate dose just before administration. In the current series of experiments using mice, the half daily human dose $(95 \mathrm{mg} / \mathrm{kg})$ was used. Manufactured DKT (m-DKT) prepared as a dried powder extract of mixing the crude herbs (Ginsen radix, $3.0 \mathrm{~g}$; Zingiberis siccatum, $5.0 \mathrm{~g}$; Zanthoxylum fructus, $2.0 \mathrm{~g}$ ) was from Tsumura \& Co. Ltd. (Tokyo, Japan) with dried powder extract of Saccharum gramorumb at a ratio of $1: 8$.

\section{Three-dimensional HPLC}

DKT was dissolved with $\mathrm{H}_{2} \mathrm{O}$, and was then filtered and analyzed by HPLC (ACQUITY UPLC; Nihon Waters K.K, Tokyo, Japan) under the following conditions. Sample $(10 \mu \mathrm{l})$ was applied to a COSMOSIL C18-MS-II column $(3.0 \times 50 \mathrm{~mm}$; Nacalai Tesuque Co., Inc., Kyoto, Japan). The mobile phase was water $\left(\mathrm{H}_{2} \mathrm{O}\right) /$ acetonitrile $\left(\mathrm{CH}_{3} \mathrm{Hn}\right)$ (9:1) for the first $10 \mathrm{~min}$, changing to a linear gradient of (1:1) over $85 \mathrm{~min}$. The flow rate was $1.0 \mathrm{ml} / \mathrm{min}$ and the oven temperature was $30{ }^{\circ} \mathrm{C}$. HPLC patterns were analyzed by absorbance at $200-340 \mathrm{~nm}$. 
Intestinal manipulation (IM) for mouse model of POI

All animals were anesthetized with isoflurane (Escain; Mylan Inc., Tokyo, Japan) or pentobarbital sodium (Somnopentyl; Kyoritsu Seiyaku Corp., Tokyo, Japan). Intestinal manipulation (IM) was performed as reported previously [21, 22]. Briefly, the distal ileal part $(10 \mathrm{~cm}$ from the ileocecal valve) was exteriorized and then gently scraped with compression along its entire length for about 3-5 min at a strength equal to general writing pressure using a sterile cotton applicator moistened with physiological saline. After manipulation, the abdomen was closed with sutures.

\section{Intestinal transit determination}

Twenty-three hours after IM with fasting, the non-absorbable marker, $80 \mu \mathrm{l}$ of $0.25 \%(\mathrm{w} / \mathrm{v})$ phenol red (PR) in phosphate buffered saline (PBS), was orally administered to mice via a gastric tube. After $1 \mathrm{~h}$, the gastrointestinal part was isolated and stomach and intestine were separated as a single stomach segment (Sto), ten small intestine segments (SI1-SI10), a single cecum segment (Cec) and three colon segments (Co1-Co3). The contents of each segment were mixed with $0.1 \mathrm{~N}$ sodium hydroxide. Proteins in the sample were precipitated by addition of $20 \%$ $\left(\mathrm{w} \mathrm{v}^{-1}\right.$ ) trichloroacetate. The optical density volume of each supernatant after centrifugation at $1600 \times g$ for $20 \mathrm{~min}$ with $0.6 \mathrm{~N}$ sodium hydroxide was then determined at $570 \mathrm{~nm}$. The volume of PR for 14 segments was calculated using a standard curve. Each geometric center (GC) of distribution for PR in 14 segments of the gastrointestinal tract was calculated using the following formula [17, 22]:

$$
\begin{aligned}
& \text { GC }=\Sigma\{(\% \text { of each fluorescence signal }) \\
& \quad \times(\text { segment number })\} \div 100
\end{aligned}
$$

Twenty-two hours after IM with fasting, mice were given a $\left[1-{ }^{13} \mathrm{C}\right]$ sodium acetate (Cambridge Isotope Laboratories, Woburn, MA, USA) labeled solid test meal and placed in test chambers. To collect air from the chambers, we used the noninvasive breath test system [23], comprising four animal chambers, a pump and breath sampling bags. Expired air was collected and measured at 5-min intervals until $30 \mathrm{~min}$, with additional measurements at 10-min intervals until 60 min. ${ }^{13} \mathrm{CO}_{2}$ levels in the trapped air were measured by POC one (Otsuka Electronics Co., Ltd., Tokyo, Japan) and are given as $\Delta^{13} \mathrm{CO}_{2}(\%)$, as reported previously [24].
Whole mount preparations

Histochemical examination was performed on wholemount muscularis preparations of the ileum. Whole-mount muscularis $(5 \mathrm{~cm}$ from ileocecal valve of the distal ileal region) samples were prepared as reported previously [23, $25,26]$. The isolated mucosa-free muscularis tissue sheets were pinned to the silicon base of dishes. The tissue sheets were stretched to $110 \%$ of their resting length on the silicon sheet and then fixed in $4 \%$ paraformaldehyde in PBS for $30 \mathrm{~min}$ at $4{ }^{\circ} \mathrm{C}$ to make a whole mount preparation $(5 \mathrm{~mm} \times 5 \mathrm{~mm}$ sheet). After fixation, whole mount were washed in PBS and were then cut and used for staining procedures.

Whole mount immunohistochemistry

Muscularis whole mounts were used for immunohistochemical analysis of CD68 and PGP9.5. Each whole mount was incubated with $0.2 \%$ triton $\mathrm{X}-100$ in PBS at room temperature (RT) for $2 \mathrm{~h}$. After blocking with $2 \% \mathrm{BSA}$ in PBS at RT for $1 \mathrm{~h}$, whole mounts were incubated overnight in primary antibody (rat anti-mouse CD68 Ab, dilution 1:1000; Serotec, Düsseldorf, Germany; and rabbit antihuman PGP9.5 poly Ab, dilution 1:1000; Cosmo Bio Co., Ltd, Tokyo, Japan) at $4{ }^{\circ} \mathrm{C}$, washed three times in PBS, incubated in $5 \%$ normal donkey and goat IgG in blocking buffer for $15 \mathrm{~min}$, followed by the appropriate secondary antibody (donkey anti-rat Alexa 488, dilution 1:500; Molecular Probes Inc., Eugene, OR; and goat anti-rabbit Alexa 568, dilution 1:500; Invitrogen, Carlsbad, CA) at RT for $90 \mathrm{~min}$. After washing three times, whole mounts were cover-slipped and inspected by confocal microscopy (ECLIPSE Ti; Nikon, Tokyo, Japan). CD68-positive cells were counted in three randomly selected fields in each specimen at a magnification of $40 \times$. The same experiment was performed four times in order to calculate mean \pm SEM.

\section{Myeloperoxidase staining}

In order to detect myeloperoxidase (MPO)-positive neutrophils, freshly prepared whole mounts were stained with PBS containing $0.1 \%(\mathrm{w} / \mathrm{v})$ Hanker-Yates reagent (Polysciences, Warrington, PA) and $0.03 \%(\mathrm{v} / \mathrm{v})$ hydrogen peroxidase (Wako Pure Chemical Industries Ltd., Osaka, Japan), and were then rinsed in PBS [27]. Cells that were obviously MPO-positive in the muscularis were counted under a microscope (BX41; Olympus Corporation, Tokyo, Japan) in three randomly selected fields for each specimen at a magnification of $40 \times$. 
Measurement of myeloperoxidase activity

MPO activity in the ileum tissue was measured as described previously, with some modifications [28]. To measure the MPO activity spectrophotometrically, ileal segment tissue homogenates prepared $24 \mathrm{~h}$ after IM were combined with TMB substrate reagent. The absorbance at $460 \mathrm{~nm}$ was measured on a spectrophotometer (Model 680; Bio Rad, Hercules, CA, USA). The units of MPO activity were divided by the colonic wet weight of the tissue.

\section{Semi-quantitative RT-PCR}

Quantitative RT-PCR was performed as described previously [26]. Oligonucleotide primers for GAPDH (NM 008084), MCP-1 (NM 011333), TNF- $\alpha$ (NM 013693), IL-6 (NM 031168), IL-1 $\beta$ (NM 008361) and iNOS (BC 062378) were designed based on the cDNA database. The forward and reverse primers and product sizes were listed in Table 1. Amplification proceeded in a PCR Thermal Cycler (Takara PCR Thermal Cycler MP; Takara Bio, Otsu-shi, Japan) using 32 cycles consisting of $94{ }^{\circ} \mathrm{C}$ for $40 \mathrm{~s}, 58{ }^{\circ} \mathrm{C}$ for $60 \mathrm{~s}$, and $72{ }^{\circ} \mathrm{C}$ for $90 \mathrm{~s}$. The products of each cycle were resolved on $2 \%$ agarose gels containing $0.1 \%$ ethidium bromide. Detectable fluorescent bands were visualized with an ultraviolet transilluminator (High Performance UV transilluminator; UVP, Upland, CA), and the density of detectable fluorescent bands was measured using NIH Image software (Image J, Ver. 1.44p).

\section{Experimental design}

Animals were randomly divided into the following experimental groups: (1) Normal, no treatment, no IM; (2) Control (IM + Vehicle), ultrapure water was orally administered at 3 days, 2 days and 1 day before, and at $6 \mathrm{~h}$ after IM; and (3) IM + DKT, $0.2 \mathrm{ml}$ of DKT with doses at one tenth $(19 \mathrm{mg} / \mathrm{kg})$ or half $(95 \mathrm{mg} / \mathrm{kg})$ the human daily dose were similarly orally administered four times to the mice via gastric tube. The group information was not blinded to the operator. To assess the effects of DKT alone, mice were randomly assigned into 2 groups: 1) Normal; and 2) Normal + DKT. After sacrifice, the muscle layer of the ileum was used for histochemical staining for MPO and immunohistochemical staining for macrophages. The $\alpha 7 n A C h$ receptor antagonist methyllycaconitine citrate (MLA; $0.0125 \mathrm{mg} / \mathrm{kg}$, s.c.) was also applied $30 \mathrm{~min}$ before each DKT administration as necessary. Mice were euthanized at $24 \mathrm{~h}$ after IM. For analysis of expression of inflammatory mediators, vehicle or DKT was given orally at 3 days, 2 days and 1 day before IM. Samples were taken after at $3 \mathrm{~h}$ after IM. Isolated and prepared whole mount smooth intestinal muscle layer was used for analysis of cytokine messenger RNA (mRNA) expression. Intestinal tissue samples were used for MPO staining. In vivo intestinal transit from 23 to $24 \mathrm{~h}$ after IM was also determined. All animals recovered rapidly from the bowel manipulation procedure (within 3 days; data not shown). We therefore evaluated the efficacy of DKT at $24 \mathrm{~h}$ after IM. Surgery is generally performed according to plan in clinical practice, except in extreme emergencies; prophylactic administration of DKT before IM may therefore have important clinical implications.

\section{Statistics}

Results are expressed as mean \pm SEM. Data were statistically evaluated using unpaired Student's $t$ test for comparisons between two groups and by one-way analysis of variance (ANOVA) followed by Dunnett's test for comparisons among three or more groups. Values of $P<0.05$ were considered to be statistically significant.
Table 1 Seqences of PCR primers and their $T_{\mathrm{m}}$ values and product sizes

\begin{tabular}{|c|c|c|c|c|}
\hline Gene (locus) & Forward primers reverse primers & $T_{\mathrm{m}}\left({ }^{\circ} \mathrm{C}\right)$ & PCR cycles & Size (bp) \\
\hline GAPDH & TGTTCCTACCCCCAATGTGT & 58 & 32 & 269 \\
\hline (NM 007778.2) & CCCTGTTGCTGTAGCCGTAT & & & \\
\hline TNF- $\alpha$ & ACGGCATGGATCTCAAAGAC & 58 & 32 & 324 \\
\hline (NM 013693) & CGGACTCCGCAAAGTCTAAG & & & \\
\hline IL-6 & TCTCTGGGAAATCGTGGAAA & 58 & 32 & 397 \\
\hline (NM 031168) & GATGGTCTTGGTCCTTAGCC & & & \\
\hline IL-1 $\beta$ & TGACGTTCCCATTAGACAGC & 58 & 37 & 497 \\
\hline (NM 008361) & TGGGGAAGGCATTAGAAACA & & & \\
\hline MCP-1 & CCCACTCACCTGCTGCTACT & 58 & 32 & 381 \\
\hline (NM 011333) & AAGGCATCACAGTCCGAGTC & & & \\
\hline iNOS & AAGAGAGTGCTGTTCCAGGT & 58 & 37 & 196 \\
\hline (BC 062378.1) & CCACCAGCTTCTTCAACGTG & & & \\
\hline
\end{tabular}




\section{Results}

Three-dimensional HPLC

HPLC profile of DKT was shown in Fig. 1. HPLC analysis revealed that the prepared DKT contained ginsenoside$\mathrm{Rg} 1$, [6]-gingerol, ginsenoside-Rb1 and [6]-shogaol. The main component detected at 75 min should be hydroxy- $\alpha$ sanshool plus hydroxy- $\beta$-sanshool, as reported previously $[10,29]$, although this was not confirmed using standard preparations.

Recovery of IM-induced intestinal transit disorder by treatment with DKT

The effects of DKT on delayed intestinal transit in the mouse POI model are summarized in Fig. 2. Approximately $6 \%$ of the orally administered labeled phenol red (PR) remained inside the stomach, while $94 \%$ was transported down the intestine to the distal end of the ileum, peaking at SI-8 in the normal group (Fig. 2a). The average calculated geometric center and gastric emptying rate in the normal group were $7.16 \pm 0.22$ and $94.42 \pm 0.85 \%$ for the 15 segments of the gastrointestinal tract, respectively (Fig. 2b, c). In the IM + Vehicle group, approximately $44 \%$ of the orally administered labeled PR remained inside the stomach, while $56 \%$ was transported to SI-1 and SI-2 (Fig. 2a). The IM group showed significantly delayed rates for the geometric center at $2.04 \pm 0.07$ and gastric emptying at $55.56 \pm 4.13$, as compared with the normal group (Fig. 2b, c). The $\mathrm{IM}+$ DKT $(95 \mathrm{mg} / \mathrm{kg}$ ) group showed significant recovery of the delayed intestinal transit caused by IM, in which $22 \%$ of the orally administered content remained in the stomach, while $78 \%$ of the transported content moved between SI-1 and SI-3, peaking in SI-3 (Fig. 2a). Both the geometric center and gastric emptying rate in IM + DKT (95 mg/kg) were significantly higher, reaching $4.11 \pm 0.37$ and $84.13 \pm 2.60$, respectively (Fig. 2b, c). In normal mice, DKT slightly but significantly increased intestinal transit and gastric emptying rate (Geometric center: normal, $7.15 \pm 0.15$, +DKT, $9.53 \pm 0.78, P<0.05$; Gastric emptying rate: normal $94.96 \pm 0.63 \%$, +DKT, $99.70 \pm$ $0.22 \%, P<0.05, n=3-5$ ), thus suggesting the prokinetic

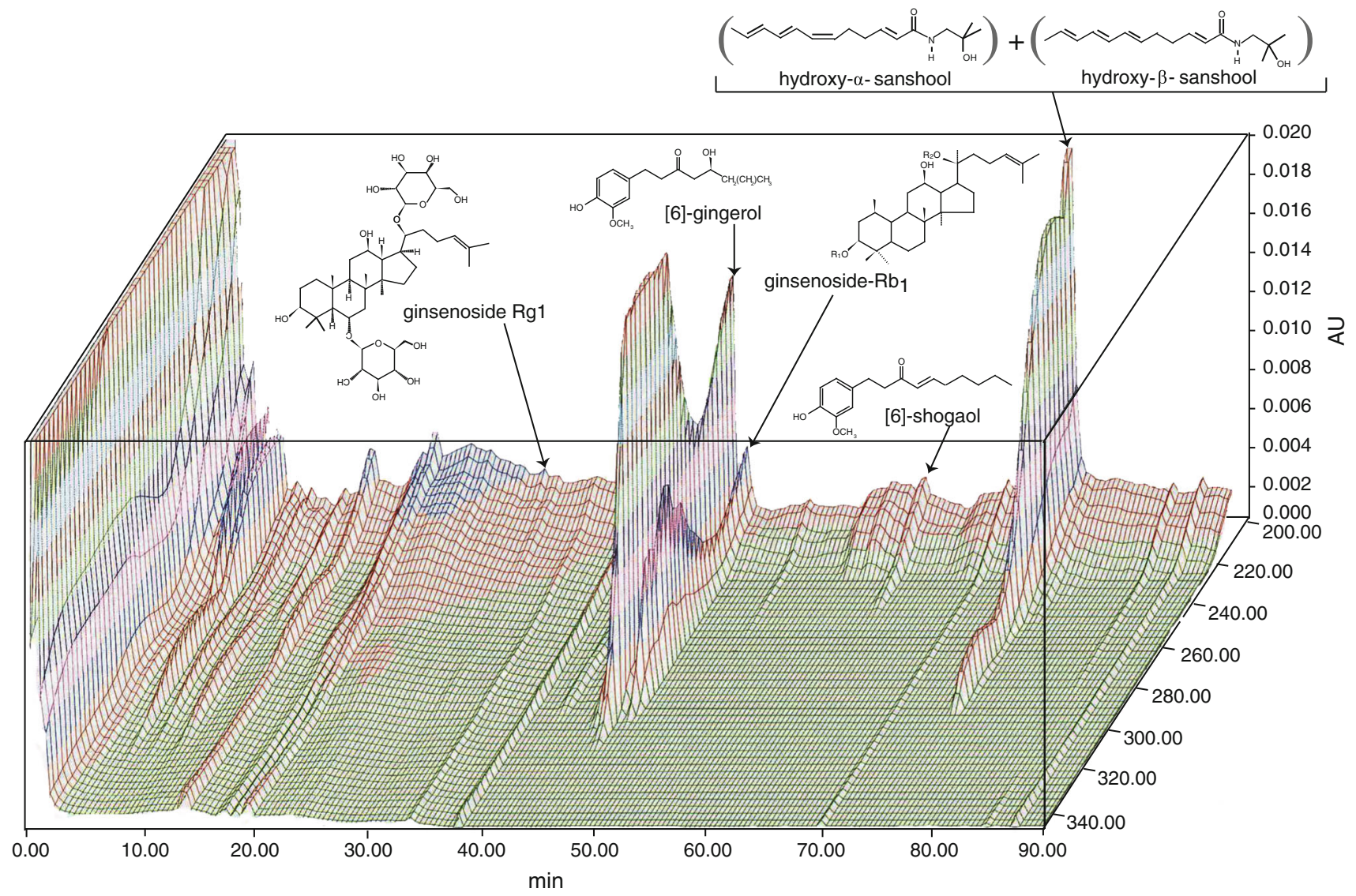

Fig. 1 HPLC profile of DKT. DKT analyzed by HPLC (ACQUITY UPLC; Nihon Waters K.K, Tokyo, Japan) under following conditions: column, COSMOSIL C18-MS-II $(3.0 \times 50 \mathrm{~mm})$; mobile phase,
$\mathrm{H}_{2} \mathrm{O}: \mathrm{CH}_{3} \mathrm{Hn}(9: 1 \rightarrow 1: 1$, linear gradient, for $95 \mathrm{~min}$ ); flow rate; $1.0 \mathrm{ml} / \mathrm{min}$; oven temperature, $30{ }^{\circ} \mathrm{C}$; injection volume, $10 \mu \mathrm{l}$ 

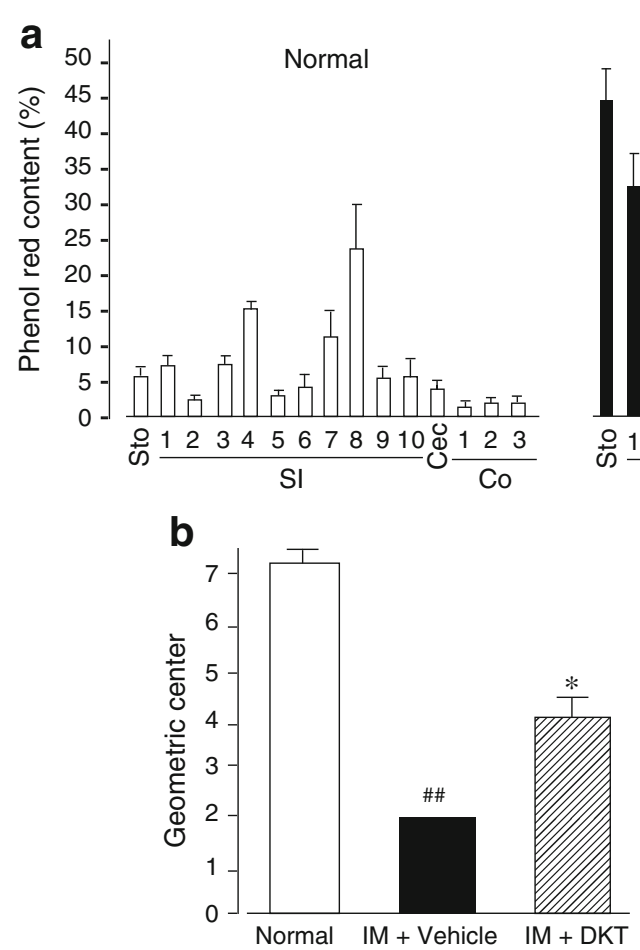

Fig. 2 Ameliorative action of DKT on gastrointestinal transit in mouse POI model. Detailed procedures are described in "Materials and methods. " a Shows distribution of PR in the normal group (left panel), at $24 \mathrm{~h}$ after IM + Vehicle (middle panel) and after $\mathrm{IM}+\mathrm{DKT}(95 \mathrm{mg} / \mathrm{kg}$, right panel $)$. Columns indicate mean $\pm \mathrm{SEM}$

potential of DKT under the current experimental conditions.

Effect of IM-induced delayed gastric emptying by treatment with DKT

To further examine an effect of DKT on gastric emptying rate by measuring ${ }^{13} \mathrm{C}$-acetate breath test. Curves obtained for ${ }^{13} \mathrm{CO}_{2}$ excretion in the two different doses of DKT + IM, IM and normal groups are shown in Fig. 3. Excretion (A) and cumulative excretion (B) of ${ }^{13} \mathrm{CO}_{2}$ in the IM group were significantly lower than those in the normal group $(P<0.01$ by ANOVA). At each time-point from 15 to $40 \mathrm{~min}$, excretion of ${ }^{13} \mathrm{CO}_{2}$ in the IM group was significantly lower $(P<0.01$ each $)$ than those of the normal group. At each time-point from 15 to $60 \mathrm{~min}$, cumulative excretion of ${ }^{13} \mathrm{CO}_{2}$ in the IM group was significantly lower $(P<0.01$ each $)$ than that in the normal group. The maximum concentration $\left(C_{\max }\right.$; $\Delta \%$ ) (Normal; $55.24 \pm 5.22, \mathrm{IM}+$ vehicle; $21.23 \pm 1.41$, $P<0.05)$ and the aria under the curve (AUC; $\Delta \% / \mathrm{min}$ ) (Normal; $1385.33 \pm 221.31, \quad \mathrm{IM}+$ vehicle; $180.75 \pm$ $18.71, P<0.01)$ were significantly decreased and the time to reach the maximum concentration $\left(T_{\max } ; \min \right)$ (Normal; $19.00 \pm 0.94, \mathrm{IM}+$ vehicle; $28.57 \pm 1.71, P<0.01)$ was significantly increased in IM.
$\mathrm{IM}+$ Vehicle $\quad I M+D K T$
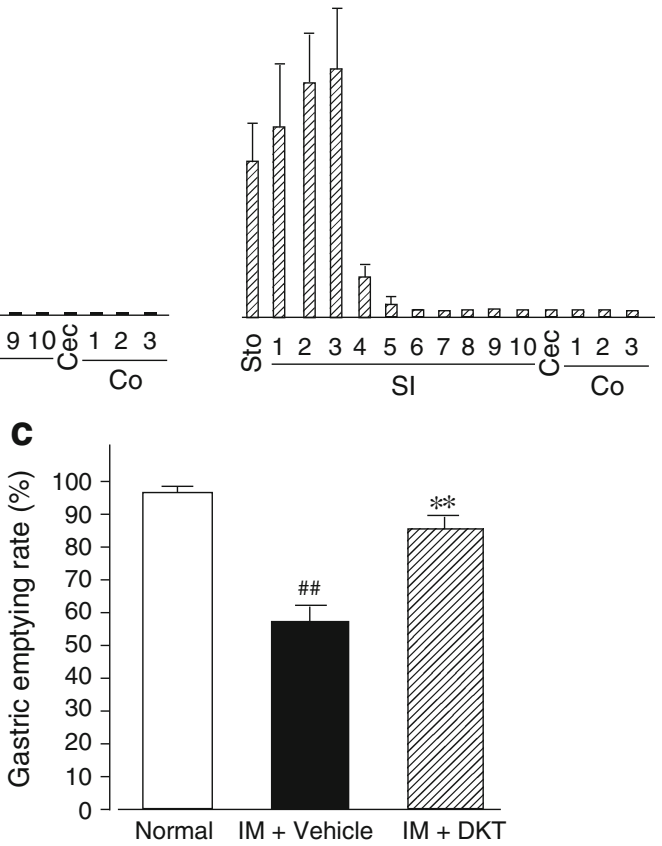

of $n=4 /$ group. b, c Show geometric center and gastric emptying rate, as calculated from a. Bars indicate mean \pm SEM. \#\#; significantly different from normal at $P<0.01$. $*$ and $* *$ are significantly different from IM + Vehicle at $P<0.05$ and $P<0.01$, respectively

Excretion of ${ }^{13} \mathrm{CO}_{2}$ in the IM + DKT $(95 \mathrm{mg} / \mathrm{kg}$ ) group significantly increased $(P<0.01$ by ANOVA) the delayed gastric emptying induced by IM but not at each time-point from 0 to $60 \mathrm{~min}$. DKT does not show the efficacy for $C_{\max }$ $(\mathrm{IM}+\mathrm{DKT} \quad 19 \mathrm{mg} / \mathrm{kg} ; \quad 28.97 \pm 2.24, \quad 95 \mathrm{mg} / \mathrm{kg}$; $32.02 \pm 3.29)$, AUC $(19 \mathrm{mg} / \mathrm{kg} ; 317.01 \pm 38.59,95 \mathrm{mg} /$ $\mathrm{kg} ; 441.35 \pm 95.53)$ and $T_{\max }(19 \mathrm{mg} / \mathrm{kg} ; 25.00 \pm 1.15$, $95 \mathrm{mg} / \mathrm{kg} ; 32.02 \pm 1.70)$. The cumulative excretion of ${ }^{13} \mathrm{CO}_{2}$ in the IM + DKT $(19 \mathrm{mg} / \mathrm{kg}$ and $95 \mathrm{mg} / \mathrm{kg})$ group significantly increased $(P<0.01$ by ANOVA) the delayed gastric emptying induced by IM but not at each time-point from 0 to $60 \mathrm{~min}$.

Amelioration of IM-induced inflammation of intestinal wall by treatment with DKT

After DKT treatment, we immunohistochemically monitored changes in MPO-stained neutrophils, and CD68positive resident and monocyte-derived macrophages, as shown in Figs. 4 and 5. In Fig. 4, MPO-stained neutrophil infiltration into the ileal muscle layer was increased in the $\mathrm{IM}+$ Vehicle group, as compared with that in the normal group. Neutrophil infiltration by IM was significantly ameliorated in the IM + DKT group. In Fig. 5, resident dendritic macrophages [30] stained by CD68 were present 


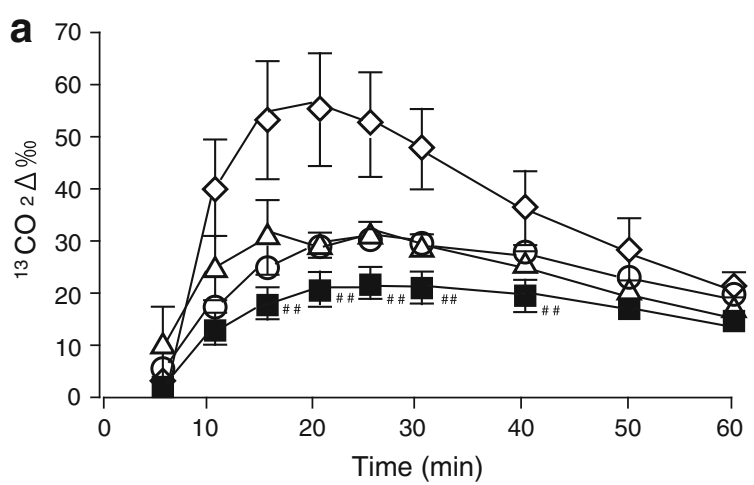

b

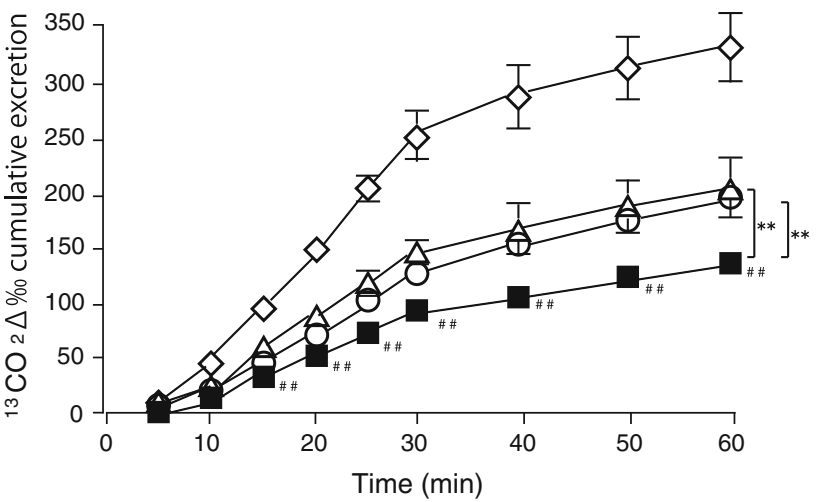

Fig. 3 Effect of DKT on excretion and cumulative excretion of ${ }^{13} \mathrm{CO}_{2}$, as calculated by ${ }^{13} \mathrm{C}$-acetate breath test in POI model mice. a, b Showed excretion and cumulative excretion curves for ${ }^{13} \mathrm{CO}_{2}$, respectively. Detailed procedures are described in "Materials and methods". Open diamonds, closed squares, open triangles and open circles indicate normal, $24 \mathrm{~h}$ after IM, IM with $15 \mathrm{mg} / \mathrm{kg}$ DKT and IM with $95 \mathrm{mg} / \mathrm{kg}$ DKT groups, respectively. \#\# are significantly difference from normal $(P<0.01)$. Symbols indicate mean \pm SEM of 5-7 experiments. $* *$ are significantly different between IM group and IM + DKT group (19 and $95 \mathrm{mg} / \mathrm{kg}$ ), respectively

in the myenteric plexus region in normal intestine [26, 31]. At $24 \mathrm{~h}$ after IM, many infiltrating monocyte-derived macrophages and activated round [30] resident macrophages were observed, as reported previously [5]. The CD68-positive macrophage population increased 6-fold in the inflamed ileal muscle layer of the intestine of the $\mathrm{IM}+$ Vehicle group, as compared with the normal group. The increased CD68-positive macrophage population was significantly inhibited in the IM + DKT group, as compared with the IM group. However, DKT had no effects on MPO-stained neutrophils or CD68-positive macrophages in the control ileal muscle layer (MPO-positive cells: normal, $3.26 \pm 1.46$ cells $/ \mathrm{mm}^{2},+$ DKT, $4.88 \pm 1.49$ cells $/ \mathrm{mm}^{2}$; CD68-positive cells: normal, $646.16 \pm 16.59$ cells $/ \mathrm{mm}^{2}$, + DKT, $626.63 \pm 29.52$ cells $/ \mathrm{mm}^{2}$ ). Neutrophil infiltration and increased CD68-positive macrophage population by IM was significantly ameliorated in manufactured DKT, $\mathrm{m}$-DKT treated group as it was in our hand-made DKT
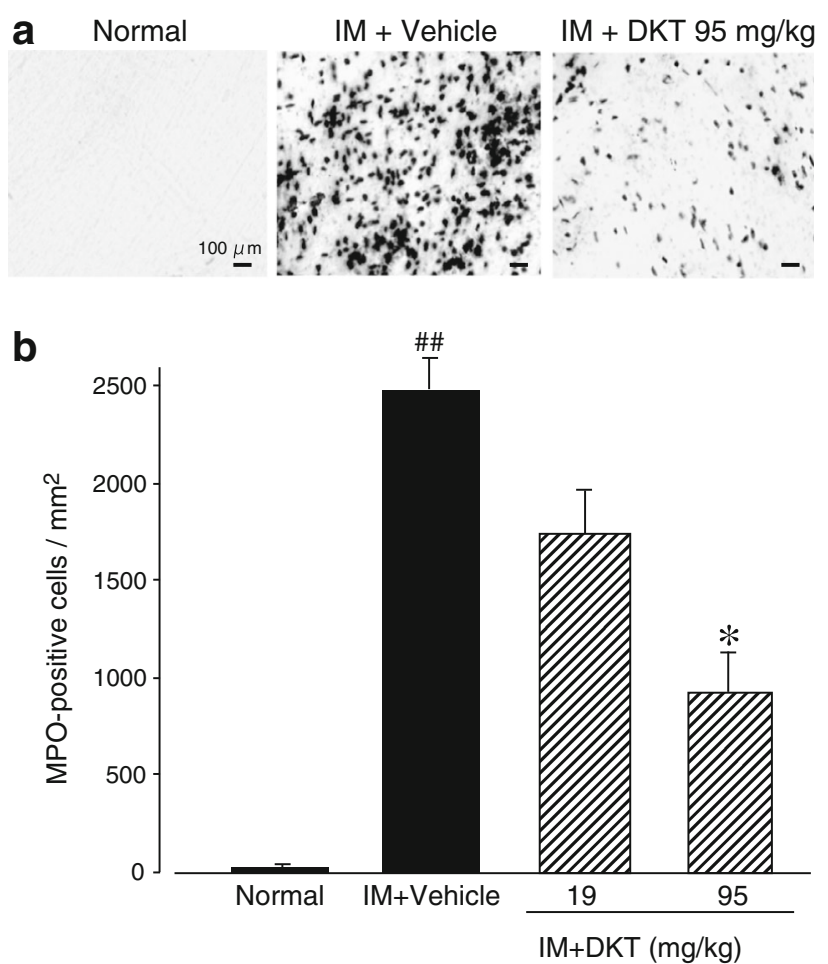

Fig. 4 Ameliorative effects of DKT on MPO-stained neutrophil infiltration in IM. a Indicates representative results for whole mount immunohistochemical staining of myenteric plexus region to detect MPO-positive neutrophils. b Shows quantification of neutrophil cells in $n=5 /$ normal and $\mathrm{IM}+\mathrm{DKT}(95 \mathrm{mg} / \mathrm{kg})$ group, $n=7 /$ $\mathrm{IM}+$ Vehicle and IM + DKT $(19 \mathrm{mg} / \mathrm{kg})$ group. Columns indicate mean \pm SEM. \#\# and *: significantly different from normal and $\mathrm{IM}+$ Vehicle at $P<0.01$ and $P<0.05$, respectively

(MPO-positive cells: normal $1.05 \pm 0.39$ cells $/ \mathrm{mm}^{2}$, IM $1653.66 \pm 121.24$ cells $/ \mathrm{mm}^{2}, \quad$ IM + DKT $1047.47 \pm$ 92.27 cells $/ \mathrm{mm}^{2}, P<0.05, \mathrm{IM}+\mathrm{m}$-DKT $603.0 \pm 90.70$ cells $/ \mathrm{mm}^{2}, P<0.01, n=4$; CD68-positive cells: normal $186.71 \pm 13.15$ cells $/ \mathrm{mm}^{2}$, IM $2095.99 \pm 144.04$ cells/ $\mathrm{mm}^{2}, \mathrm{IM}+$ DKT $1484.53 \pm 70.11$ cells $/ \mathrm{mm}^{2}, P<0.05$, $\mathrm{IM}+\mathrm{m}$-DKT $\quad 1515.12 \pm 71.51$ cells $/ \mathrm{mm}^{2}, \quad P<0.05$, $n=4)$.

Inhibition of IM-induced mRNA expression of inflammatory mediators by treatment with DKT

It has been reported that monocyte chemoattractant protein-1 (MCP-1) and tumor necrosis factor alpha (TNF- $\alpha$ ) and IL- 6 are the most important chemokines/cytokines for inflammation of POI in mice [17, 32]. We thus investigated the effects of DKT on mRNA expression of MCP-1, TNF$\alpha$, IL- 6 at $3 \mathrm{~h}$ after IM by semi-quantitative RT-PCR. In case of IL-1 $\beta$, we measured mRNA expression at $6 \mathrm{~h}$ after IM, because preliminary data indicated that IL- $1 \beta$ mRNA expression did not increase at $3 \mathrm{~h}$ after IM (data not shown). In addition, motility disorder mediated by IM is 

DKT on CD68-positive macrophage infiltration in IM. a Indicates representative results for whole mount immunohistochemical staining of myenteric plexus region to detect CD68-positive macrophages. b Shows quantification of macrophage cells in $n=5 /$ normal and $\mathrm{IM}+$ DKT $(95 \mathrm{mg} / \mathrm{kg})$ group, $n=7 / \mathrm{IM}+$ Vehicle and $\mathrm{IM}+$ DKT (19 mg/kg) group, independent experiments. Columns indicate

mean \pm SEM. \#\# and *: significantly different from normal and IM + Vehicle at $P<0.01$ and $P<0.05$, respectively. Position of myenteric plexus region was confirmed by staining with protein gene product 9.5 , which detects myenteric nerve plexus. Red signals indicate PGP9.5positive myenteric nerves. Green signals indicate CD68positive macrophages
Fig. 5 Ameliorative effects of

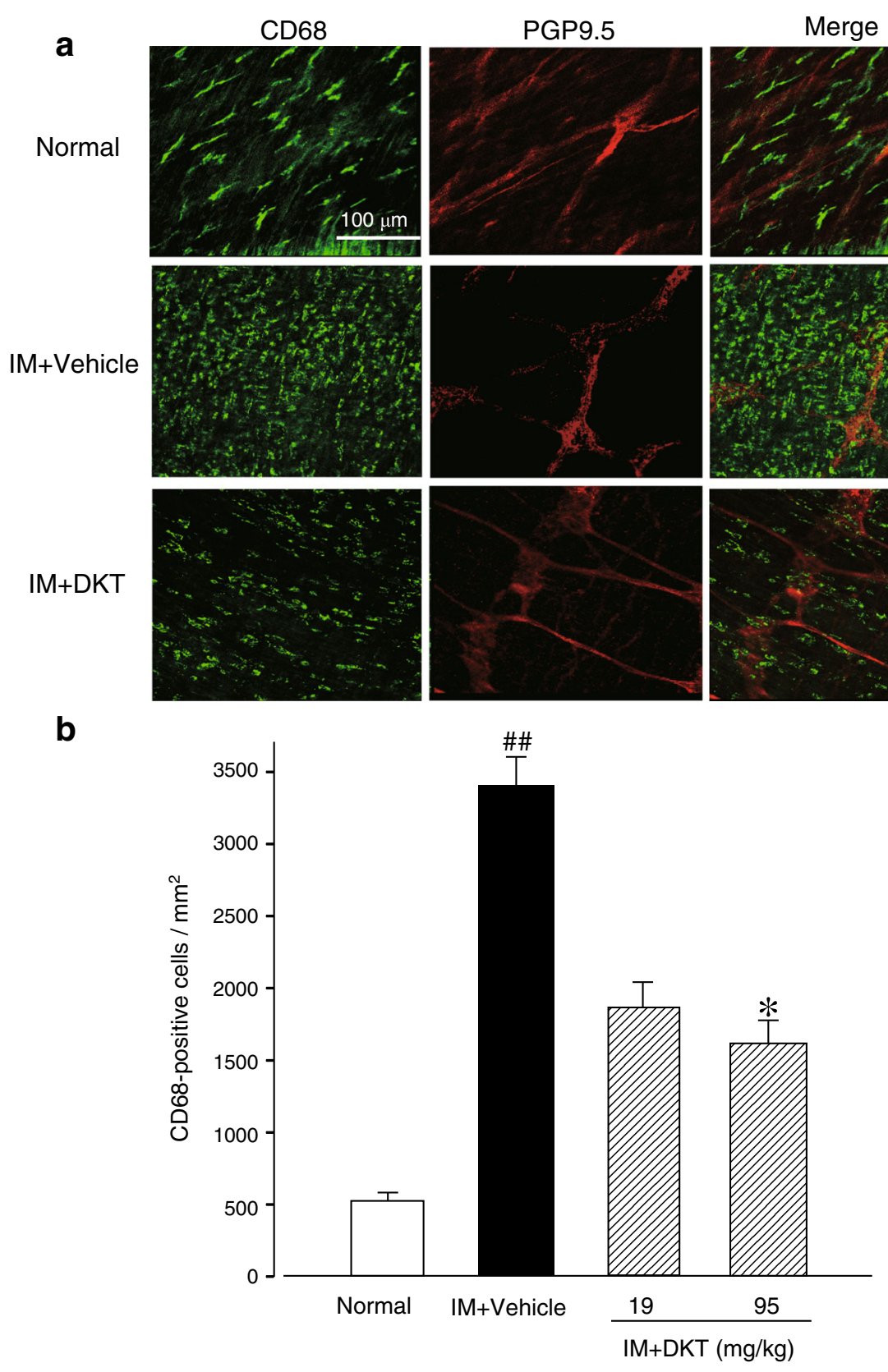

known to be induced by nitric oxide (NO) through inducible nitric oxide synthase (iNOS) $[17,32]$ in smooth muscle cell. So we also investigated effect of iNOS mRNA expression at $6 \mathrm{~h}$ after IM. It has been reported that IL-1 $\beta$ upregulated in inflammatory lesion of POI model [5, 17]. In this study, however, mRNA expression of IL-1 $\beta$ did not significantly increased in POI model mice.

As shown in Fig. 6, mRNA expressions of MCP-1 and TNF- $\alpha$ were significantly elevated in the IM + Vehicle group. IL-6 and iNOS genes also showed an upward trend in IM (Dunnet's test values: IL-6; $P=0.06$, iNOS; $P=0.44)$. mRNA expression of TNF- $\alpha$ and MCP-1 were significantly inhibited in the IM + DKT group, as compared with the IM + Vehicle group. The IM-induced increase in IL-6 and iNOS mRNA expressions also showed a downward trend in DKT-treated mice (Dunnet's test values: IL-6; $P=0.25$, iNOS; $P=0.29$ ).

Attenuation of DKT-induced anti-inflammatory activity by MLA

The effects of MLA on anti-inflammatory activity of DKT in the mouse POI model are summarized in Figs. 7 and 8. As shown in Fig. $6 \mathrm{~b}$ and c, MLA partly attenuated anti-inflammatory activity by DKT, as tissue MPO activity and MPO-positive neutrophil numbers were inhibited when compared with the IM + Vehicle group, respectively. 

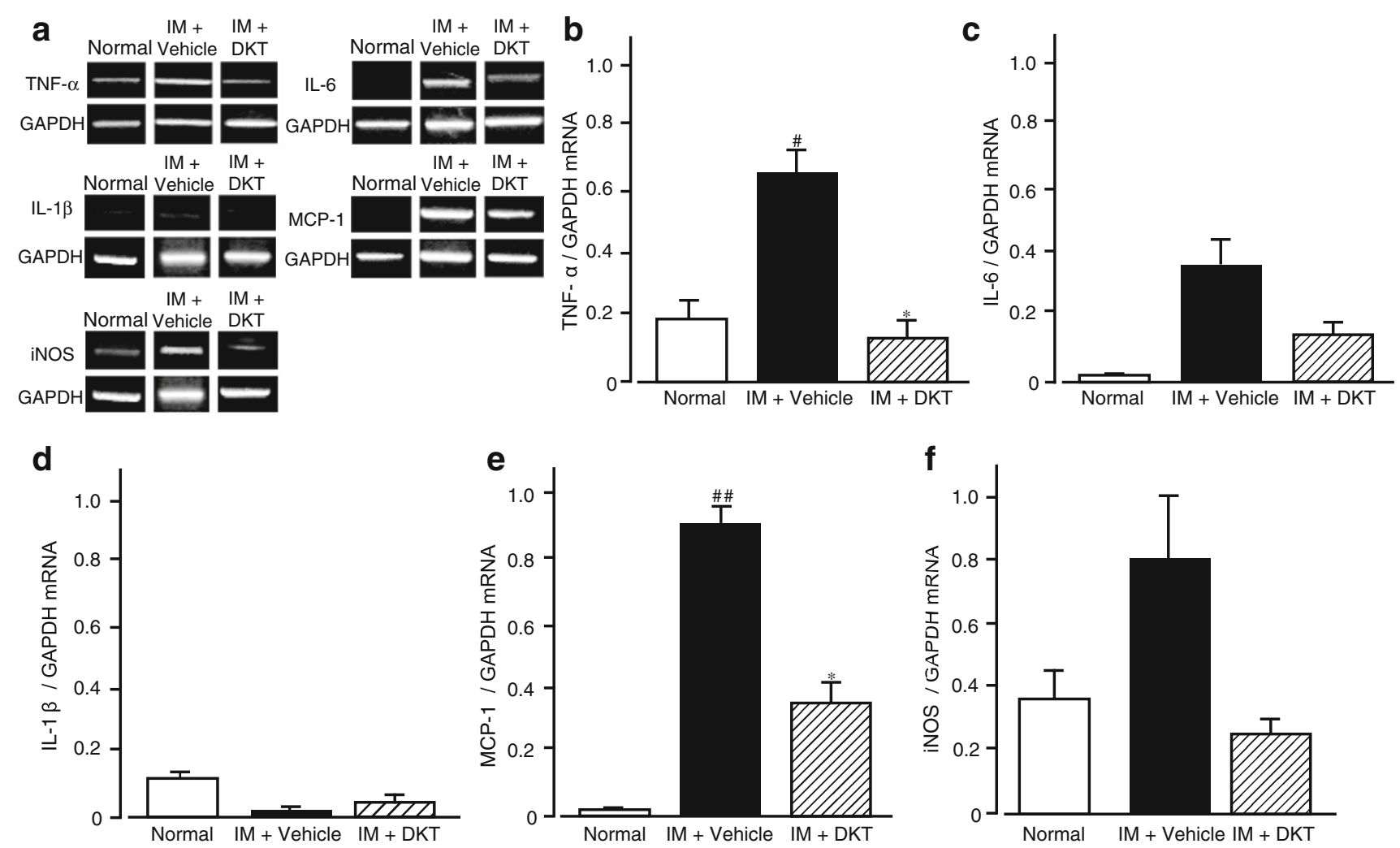

Fig. 6 Effects of DKT on mRNA expression of inflammatory mediators in inflamed muscle layer of small intestine in mouse POI model. a Showed typical results of RT-PCR. b-f Showed quantitative results of mRNA expression of TNF- $\alpha$, IL-6, IL-1 $\beta$, MCP-1 and
iNOS. Bars indicate mean \pm SEM from $n=4$ /group. \# and \#\#; significantly different from normal at $P<0.05$ and $P<0.01$, respectively. *: significantly different from IM + Vehicle at $P<0.05$
Fig. 7 Ameliorative effects of DKT and negative effects of MLA on MPO activity and MPO-positive neutrophil infiltration in mouse POI model. a, c Show representative images of MPO-positive neutrophil infiltration into myenteric plexus region and quantification results from $n=4 /$ normal and $\mathrm{IM}+$ Vehicle group, $n=5 /$ $\mathrm{IM}+\mathrm{DKT}+$ MLA group. b Shows results for MPO activity. Columns indicate mean \pm SEM from $n=4$ / group. \#\#: significantly different from normal at $P<0.01$. * and ** are significantly different from IM at $P<0.05$, $P<0.01 . \psi$ : significantly different between IM + DKT and IM + DKT + MLA at $P<0.05$ a Normal

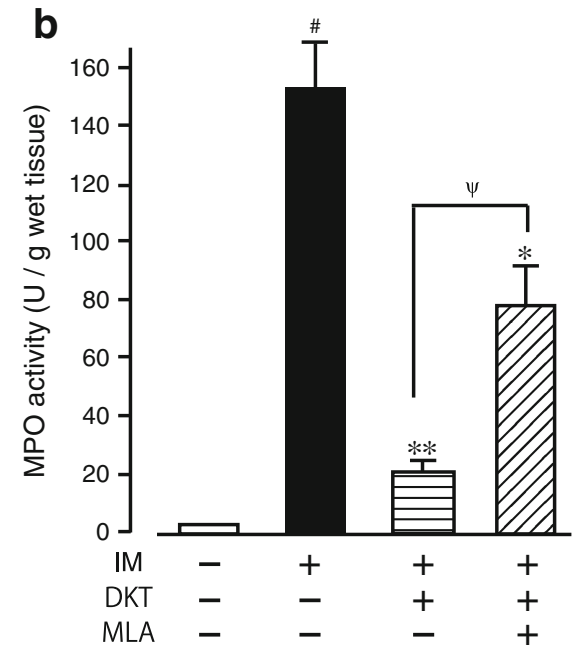

$\mathrm{IM}+\mathrm{DKT}$

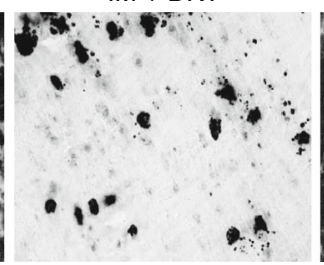

$\mathrm{IM}+\mathrm{DKT}+\mathrm{MLA}$
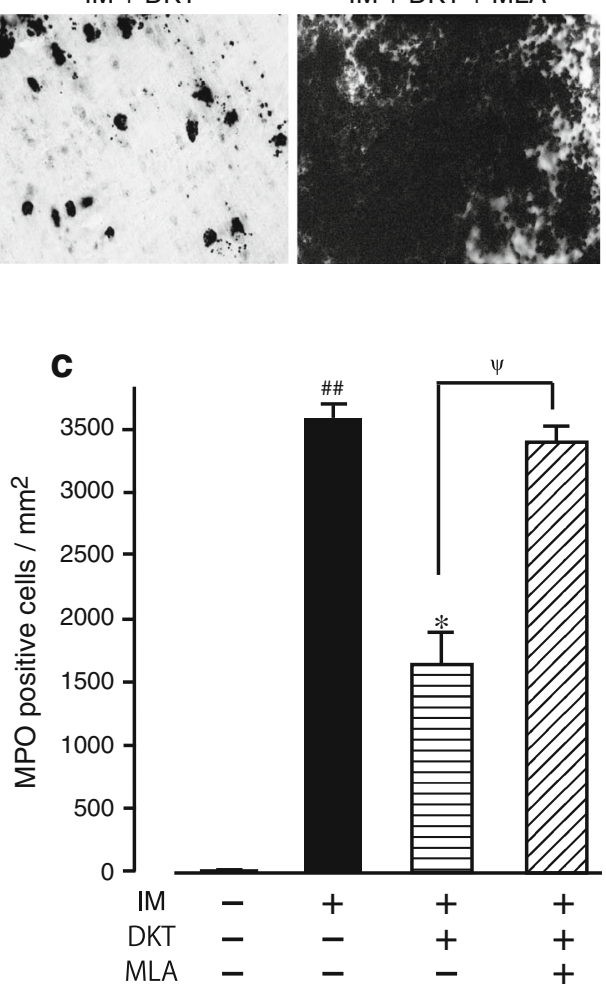
Fig. 8 Ameliorative effects of DKT and negative effects of MLA on CD68-positive macrophage infiltration in mouse POI model. a, b Show representative images of CD68positive macrophage infiltration into the myenteric plexus region and quantification results.

Columns indicate mean \pm SEM

from $n=4$ /normal,

$\mathrm{IM}+$ Vehicle and IM + DKT

group, $n=5$ /

$\mathrm{IM}+\mathrm{DKT}+$ MLA group. \#\#

and *: significantly different

from normal and IM at

$P<0.01, P<0.05$,

respectively
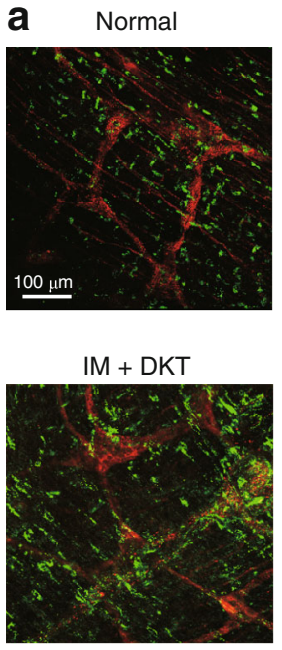

IM

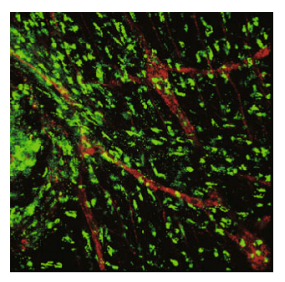

$\mathrm{IM}+\mathrm{DKT}+\mathrm{MLA}$

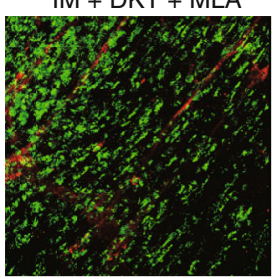

b

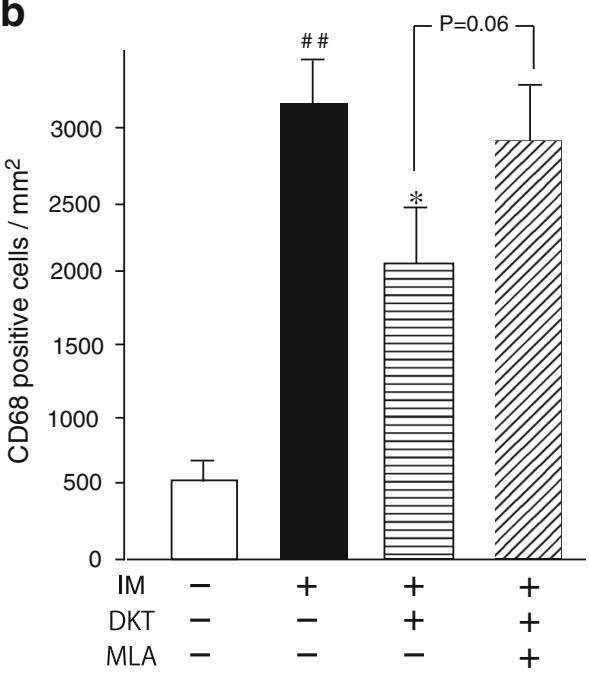

Similar results were obtained for CD-68-positive macrophages. As shown in Fig. 8, MLA came in predisposed to attenuated the DKT-induced inhibition of macrophage infiltration by IM, although IM + MLA group was no significantly different from IM group $(P=0.06, n=5)$. We confirmed that MLA itself had no effect on MPO activity, the immunohistochemical properties of neutrophils or CD68-positive macrophages in normal mice (MPO activity: normal, $10.01 \pm 0.97 \mathrm{U} / \mathrm{g}$ wet tissue, +MLA, $36.80 \pm 4.26 \mathrm{U} / \mathrm{g}$ wet tissue; MPO-positive cells: normal, $15.47 \pm 1.53$ cells $/ \mathrm{mm}^{2}$, + MLA, $15.19 \pm 1.49$ cells $/ \mathrm{mm}^{2}$; CD68-positive cells: normal, $429.67 \pm 45.95$ cells $/ \mathrm{mm}^{2}$, + MLA, $261.50 \pm 9.76$ cells $/ \mathrm{mm}^{2}$ ). In addition, MLA did not contribute to increasing inflammation by IM, as assessed by MPO activity, MPO-positive neutrophils and CD68-positive macrophages at the concentrations used in this study ( $n=2$, data not shown).

Reduction in DKT-induced inhibition of macrophage populations in $\alpha 7 \mathrm{nAChR}$ KO mice

Figure 9 shows the anti-inflammatory activity of DKT in $\alpha 7 \mathrm{nAChR}$ KO mice, with reference to that in wild-type mice (C57BL/6J). In wild-type mice, the MPO-positive infiltrating neutrophil and CD68-positive macrophage populations increased in the IM + Vehicle group, as was seen in $\mathrm{BALB} / \mathrm{c}$ mice, and these increases were significantly inhibited in the IM + DKT group, as compared with the IM + Vehicle group.

In $\alpha 7 n A C h R$ KO mice, MPO-positive infiltrating neutrophils and CD68-positive macrophages were also elevated in the IM + Vehicle group. This inflammatory cell infiltration in IM + Vehicle group was not altered in $\mathrm{KO}$ mice when compared with wild-type mice. The attenuating effects of DKT on increased MPO-positive infiltrating
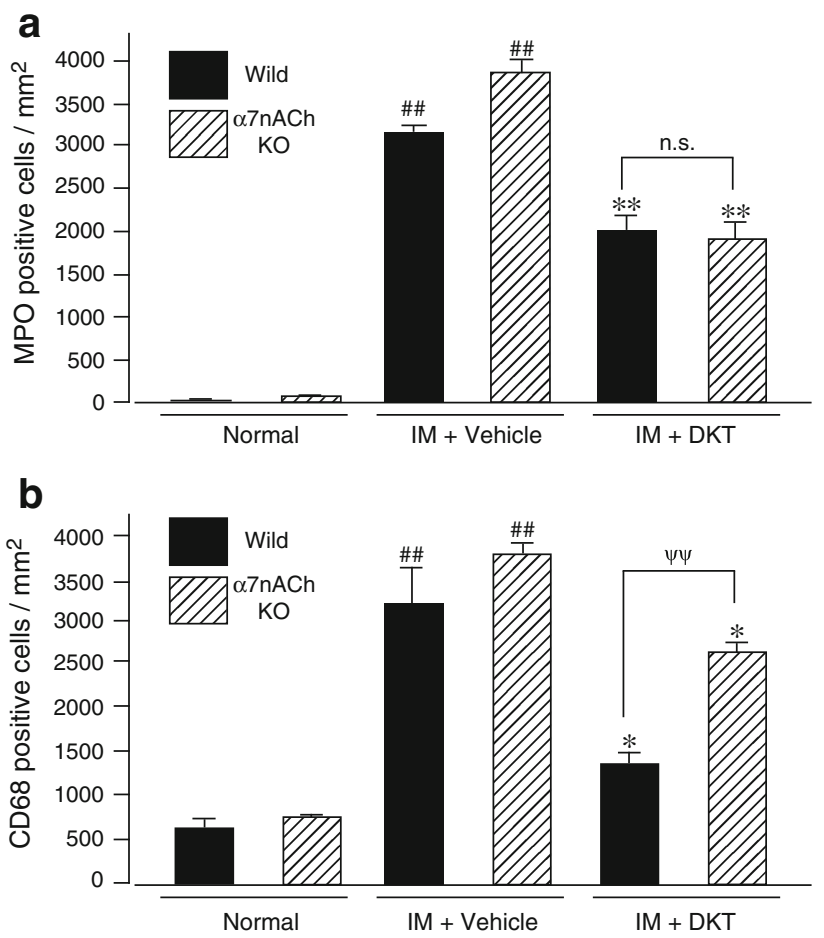

Fig. 9 Ameliorative effects of DKT on MPO- and CD68-positive neutrophils and macrophage infiltration in wild-type and $\alpha 7 \mathrm{nAChR}$ KO mice. a, b Show the effects of DKT on MPO-positive neutrophil and CD68-positive macrophage infiltration induced by IM, respectively. Columns represent mean \pm SEM from $n=7 /$ wild-type mice, $n=8 /$ normal and IM + Vehicle group in $\alpha 7 n A C h R$ KO mice, $n=9 / \mathrm{IM}+\mathrm{DKT}$ group in $\alpha 7 \mathrm{nAChR}$ KO mice. Wild-type mice are C57BL/6J mice and $\alpha 7 \mathrm{nAChR} \mathrm{KO}$ mice are of C57BL/6J background. \#\#: significantly different from normal at $P<0.01$. * and **: significantly different between IM and IM + DKT at $P<0.05$ and $P<0.01$, respectively. $\psi \psi$ : significantly different between wild-type mice and $\alpha 7 \mathrm{nAChR} \mathrm{KO}$ mice at $P<0.01$

neutrophils were maintained, which was similar to the trend seen in wild-type mice. On the other hand, the attenuating effects of DKT on infiltrating CD68-positive 
macrophages by IM were significantly reduced in $\alpha 7 \mathrm{nAChR}$ KO mice when compared with wild-type mice, indicating that the DKT-induced ameliorative effects on CD68 macrophage infiltration by IM is partly dependent on $\alpha 7 \mathrm{nAChR}$ activation. DKT had no effects on cell numbers of either neutrophils or macrophages in the control ileal muscle layer (MPO-positive cells: normal, $7.63 \pm 1.23$ cells $/ \mathrm{mm}^{2},+\mathrm{DKT}, 6.63 \pm 0.90$ cells $/ \mathrm{mm}^{2}$; CD68-positive cells: normal, $692.68 \pm 51.93$ cells $/ \mathrm{mm}^{2}, \quad$ +DKT, $706.75 \pm 68.17$ cells $/ \mathrm{mm}^{2}$ ).

\section{Discussion}

We investigated here whether DKT ameliorates the intestinal transit dysfunction and the delayed gastric emptying seen in the mouse POI model. DKT significantly recovered the intestinal transit. The calculated gastric emptying rate was also recovered by DKT as shown in Fig. 2c. These results in the mouse POI model agree with the DKT data obtained in the rat POI model $[12,13]$. We further directly measured gastric emptying ability by using ${ }^{13} \mathrm{C}$-acetate breath test, and investigated effect of DKT on the delayed gastric emptying induced by IM. Results indicated that DKT appears to have a little ameliorative effect on the delayed gastric emptying by IM as monitored with ${ }^{13} \mathrm{C}$ acetate breath test. These results support the view that DKT accelerates motility in the lower gastrointestinal tract, but has no effects on gastric emptying in healthy humans [7]. DKT-induced recovery of delayed gastric emptying rate monitored by intestinal transit test (Fig. 2c) might be apparent recovery mediated through amelioration of intestinal transit by DKT. Phenol red was just retained inside stomach by delayed intestinal transit induced by IM. Ameliorative action of DKT for lower intestinal transit might be able to recover the delayed gastric emptying rate by IM. In this study, we further showed for the first time that DKT significantly suppresses neutrophil and macrophage infiltration induced by IM, thus suggesting that DKT exerts an anti-inflammatory effect in POI. These findings indicate that clinical amelioration of POI by DKT is related to improvements in both in gastrointestinal motility and inflammation. Our data may therefore provide new insights into the use of DKT in the treatment of POI.

To date, several mechanisms for the gastroprokinetic action of DKT have been posited. First, DKT accelerates ACh release from cholinergic myenteric neurons mediated by activation of $5-\mathrm{HT}_{3} \mathrm{R}$ and $5-\mathrm{HT}_{4} \mathrm{R}$ [12-14], and smooth muscles contract due to the released ACh through stimulation of muscarinic receptors $\left(M_{2} R\right.$ and $\left.M_{3} R\right)$. Second, it has been reported that DKT raises plasma levels of motilin, a gastrointestinal polypeptide hormone, and this improves morphine-induced constipation in cancer patients and intestinal motility dysfunction in conscious dogs [33, 34]. Third, DKT induces the release of substance $\mathrm{P}$ from primary sensory nerves through the vanilloid receptors on intramucosal terminal sensory nerves, and this contracts smooth muscle $[35,36]$. In recent years, it was reported that pharmacological modulation of transient receptor potential vanilloid type1 (TRPV1) is a possible therapeutic option in POI [37], and this may be one of the mechanisms responsible for the gastroprokinetic activity of DKT [37]. The efficacy of DKT against POI has largely been explained to date by improvements in gastrointestinal motility and increased blood flow [19].

On the other hand, there have also been several reports on the anti-inflammatory effects of DKT in inflammatory diseases. It has been reported that DKT improves intestinal blood flow by increasing CGRP and substance P levels in plasma, which regulate the growth of bacterial flora, as well as inflammatory cytokine and cyclooxygenase- 2 (COX-2) production in the intestine [38]. In an another report, the vasodilatory effects due to up-regulation of the ADM and CGRP system were thought to have therapeutic and preventive effects on intestinal inflammation in Crohn's disease (CD) [39], and DKT was thought to improve CD by increasing ADM and CGRP levels [19, 20]. In addition, it was reported that postoperative DKT administration significantly suppressed CRP and postoperative inflammation following surgery for colorectal cancer [18]. However, it still remains unclear how DKT acts against inflammation on POI.

In the present study, we found that DKT markedly reduces inflammatory cell infiltration into the inflamed muscle region, thus suggesting potent anti-inflammatory effects of DKT on POI. Local inflammation in the intestinal muscle layer is known to be closely correlated with gastrointestinal motility disorder [3, 17, 23, 40], and amelioration of inflammation in the intestinal muscle layer improves motility disorder $[5,17,30]$. Although intestinal transit in healthy mice is improved by DKT in this study, improvement by DKT in intestinal transit in POI mice is more effective than in healthy mice. Taken together, these results have led us to hypothesize that the ameliorative effects of DKT on gastrointestinal motility in POI are mediated by anti-inflammatory action against IM, in addition to the gastrointestinal prokinetic action of DKT.

We next investigated effect of DKT on mRNA expressions of inflammatory mediators induced by IM. IM upregulated the mRNA expression of cytokine/chemokine such as TNF- $\alpha$, IL-6, IL-1 $\beta$ and MCP-1 [17]. Inducible NOS (iNOS) gene is also upregulated by IM, which in turn induces motility disorder in POI [17]. Our observations suggest the inhibition of TNF- $\alpha$ and MCP-1 by DKT, and this agrees with a report on the anti-inflammatory efficacy of DKT via inhibition of TNF- $\alpha$ in rat and mouse CD 
models [29, 41]. The IM-induced increase in IL-6 and iNOS mRNA expressions also showed a downward trend in DKT-treated mice. Taken together, DKT has an inhibitory action of inflammatory mediator genes expression induced by IM.

DKT exerts its gastroprokinetic activity through activation of $5-\mathrm{HT}_{3} \mathrm{R}$ and/or $5-\mathrm{HT}_{4} \mathrm{R}$ of the vagal afferent, which stimulates cholinergic transmission in the myenteric plexus [13]. We previously found that the $5-\mathrm{HT}_{4} \mathrm{R}$ agonist mosapride citrate induced anti-inflammatory effects via activation of $\alpha 7 \mathrm{nAChR}$ on muscularis-activated macrophages through the release of ACh from cholinergic nerves in the myenteric plexus [5]. Subsequently, activation of $\alpha 7 n A C h R$ suppressed inflammatory cytokine production by macrophages, which improved POI [42]. So we further investigated the effects of the $\alpha 7 \mathrm{nAChR}$ antagonist MLA on DKT-induced anti-inflammatory actions in POI. The results suggested that MLA significantly inhibited the DKT-mediated anti-inflammatory activity, as monitored by infiltrating macrophages and neutrophils. These results suggest that DKT-induced anti-inflammatory activity in POI may be mediated through $\alpha 7 \mathrm{nAChR}$ activation. In fact, another report supports our observation that the selective $\alpha 7 n A C h R$ agonist AR-R17779 prevents inflammation in POI [43]. In the rat POI model, we confirmed that infiltrating macrophages and activated resident macrophages, but not infiltrating neutrophils, had an affinity for $\alpha$-bungarotoxin [5]. We therefore speculated that these $\alpha$ bungarotoxin-bound macrophages may be effector cells in the anti-inflammatory action of DKT.

We further confirmed this conclusion by using $\alpha 7 n A C h R$ KO mice. Interestingly, DKT-induced antiinflammatory actions were partly suppressed in $\alpha 7 \mathrm{nAChR}$ KO mice. With regard to macrophage infiltration, the DKT-induced ameliorative effects were partly but significantly reduced in $\alpha 7 \mathrm{nAChR} \mathrm{KO}$ mice, suggesting that, at least in part, DKT-induced inhibitory effects on macrophage infiltration could be mediated through $\alpha 7 \mathrm{nAChR}$. In contrast, in the case of neutrophil infiltration, the DKTinduced inhibitory action was not affected in $\alpha 7 \mathrm{nAChR} \mathrm{KO}$ mice, indicating that DKT-induced inhibitory action for neutrophil infiltration may not be mediated through $\alpha 7 n A C h R$. Taken together, these results suggest that $\alpha 7 n A C h R$ and other subtypes of nicotinic receptors are involved in the DKT-induced anti-inflammatory effects. Recent work also supports the notion that nicotinic inhibition of macrophage activation involves other receptors, in addition to $\alpha 7 \mathrm{nAChR}$ [43]. One possible candidate is $\alpha 4 \beta 2$ heteropentameric nAChR [44]. It has been reported that activation of this nAChR subtype also inhibits transactivational activity of the transcription factor NF- $\kappa B$ p 65 . However, it has been reported that MLA only has binding affinity for the $\alpha 6$ and $\alpha 7$ isoforms of nAChR [45]. Further investigation is thus necessary in order to clarify other types of nAChR activated by DKT.

In conclusion, DKT may serve as a novel therapeutic agent against POI, as characterized by its anti-inflammatory potency, in addition to its gastrointestinal prokinetic action. The anti-inflammatory potency of DKT in POI may be mediated through the activation of $\mathrm{nAChRs}$ via $\mathrm{ACh}$ release from the myenteric plexus nerve. DKT-induced anti-inflammatory activity may be partly mediated by the activation of $\alpha 7 \mathrm{nAChR}$. Interestingly, it was reported that herb zanthoxylum fruit and maltose syrup include target component to induce prokinetic ability [12]. So we are preparing to undertake a process to identify the target herb(s) in DKT to induce anti-inflammatory ability.

Acknowledgments This work was supported by a Grant-in-Aid for Scientific Research from the Ministry of Education, Japan (MH, HO). We are grateful to Ominedo Pharmaceutical Industry Co. Ltd. for three-dimensional HPLC analysis.

Conflict of interest The authors declare that they have no conflict of interest.

Open Access This article is distributed under the terms of the Creative Commons Attribution Noncommercial License which permits any noncommercial use, distribution, and reproduction in any medium, provided the original author(s) and the source are credited.

\section{References}

1. Livingston EH, Passaro EP Jr. Postoperative ileus. Dig Dis Sci. 1990;35(1):121-32.

2. Chan DC, Liu YC, Chen CJ, Yu JC, Chu HC, Chen FC, et al. Preventing prolonged post-operative ileus in gastric cancer patients undergoing gastrectomy and intra-peritoneal chemotherapy. World J Gastroenterol. 2005;11(31):4776-81.

3. Shibata Y, Toyoda S. Effects of prostaglandin F2alpha and cisapride on small intestinal activity during the early postoperative period in humans. Surg Today. 1998;28(8):787-91.

4. Narita K, Tsunoda A, Takenaka K, Watanabe M, Nakao K, Kusano M. Effect of mosapride on recovery of intestinal motility after hand-assisted laparoscopic colectomy for carcinoma. Dis Colon Rectum. 2008;51(11):1692-5.

5. Tsuchida Y, Hatao F, Fujisawa M, Murata T, Kaminishi M, Seto Y, et al. Neuronal stimulation with 5-hydroxytryptamine 4 receptor induces anti-inflammatory actions via alpha7nACh receptors on muscularis macrophages associated with postoperative ileus. Gut. 2011;60(5):638-47.

6. Bauer AJ, Boeckxstaens GE. Mechanisms of postoperative ileus. Neurogastroenterol Motil. 2004;16(Suppl 2):54-60.

7. Manabe N, Camilleri M, Rao A, Wong BS, Burton D, Busciglio I, et al. Effect of daikenchuto (TU-100) on gastrointestinal and colonic transit in humans. Am J Physiol Gastrointest Liver Physiol. 2010;298(6):G970-5.

8. Itoh T, Yamakawa J, Mai M, Yamaguchi N, Kanda T. The effect of the herbal medicine dai-kenchu-to on post-operative ileus. J Int Med Res. 2002;30(4):428-32.

9. Yasunaga H, Miyata H, Horiguchi H, Kuwabara K, Hashimoto H, Matsuda S. Effect of the Japanese herbal kampo medicine dai- 
kenchu-to on postoperative adhesive small bowel obstruction requiring long-tube decompression: a propensity score analysis. Evid Based Complement Alternat Med. 2011;2011:264289.

10. Takeda T, Kamiura S, Kimura T. Effectiveness of the herbal medicine daikenchuto for radiation-induced enteritis. J Altern Complement Med. 2008;14(6):753-5.

11. Endo S, Nishida T, Nishikawa K, Nakajima K, Hasegawa J, Kitagawa $\mathrm{T}$, et al. Dai-kenchu-to, a Chinese herbal medicine, improves stasis of patients with total gastrectomy and jejunal pouch interposition. Am J Surg. 2006;192(1):9-13.

12. Tokita Y, Yuzurihara M, Sakaguchi M, Satoh K, Kase Y. The pharmacological effects of Daikenchuto, a traditional herbal medicine, on delayed gastrointestinal transit in rat postoperative ileus. J Pharmacol Sci. 2007;104(4):303-10.

13. Fukuda H, Chen C, Mantyh C, Ludwig K, Pappas TN, Takahashi T. The herbal medicine, Dai-Kenchu-to, accelerates delayed gastrointestinal transit after the operation in rats. J Surg Res. 2006;131(2):290-5.

14. Shibata C, Sasaki I, Naito H, Ueno T, Matsuno S. The herbal medicine Dai-Kenchu-Tou stimulates upper gut motility through cholinergic and 5-hydroxytryptamine 3 receptors in conscious dogs. Surgery. 1999;126(5):918-24.

15. Kalff JC, Carlos TM, Schraut WH, Billiar TR, Simmons RL, Bauer AJ. Surgically induced leukocytic infiltrates within the rat intestinal muscularis mediate postoperative ileus. Gastroenterology. 1999;117(2):378-87.

16. Kalff JC, Schraut WH, Billiar TR, Simmons RL, Bauer AJ. Role of inducible nitric oxide synthase in postoperative intestinal smooth muscle dysfunction in rodents. Gastroenterology. 2000;118(2):316-27.

17. Wehner S, Behrendt FF, Lyutenski BN, Lysson M, Bauer AJ, Hirner A, et al. Inhibition of macrophage function prevents intestinal inflammation and postoperative ileus in rodents. Gut. 2007;56(2):176-85.

18. Yoshikawa K, Shimada M, Nishioka M, Kurita N, Iwata T, Morimoto S, et al. The effects of the Kampo medicine (Japanese herbal medicine) "Daikenchuto" on the surgical inflammatory response following laparoscopic colorectal resection. Surg Today. 2011;42(7):646-51.

19. Kono T, Koseki T, Chiba S, Ebisawa Y, Chisato N, Iwamoto J, et al. Colonic vascular conductance increased by Daikenchuto via calcitonin gene-related peptide and receptor-activity modifying protein 1. J Surg Res. 2008;150(1):78-84.

20. Murata P, Kase Y, Ishige A, Sasaki H, Kurosawa S, Nakamura T. The herbal medicine Dai-kenchu-to and one of its active components [6]-shogaol increase intestinal blood flow in rats. Life Sci. 2002;70(17):2061-70.

21. Schmidt J, Stoffels B, Moore BA, Chanthaphavong RS, Mazie AR, Buchholz BM, et al. Proinflammatory role of leukocytederived Egr-1 in the development of murine postoperative ileus. Gastroenterology. 2008;135(3):926-36, 36 e1-2.

22. Schwarz NT, Kalff JC, Turler A, Engel BM, Watkins SC, Billiar TR, et al. Prostanoid production via COX-2 as a causative mechanism of rodent postoperative ileus. Gastroenterology. 2001;121(6):1354-71.

23. Uchida M, Endo N, Shimizu K. Simple and noninvasive breath test using 13C-acetic acid to evaluate gastric emptying in conscious rats and its validation by metoclopramide. J Pharmacol Sci. 2005;98(4):388-95.

24. Hoshino T, Oikawa T, Endo M, Hanawa T. The utility of noninvasive (13)C-acetate breath test using a new solid test meal to measure gastric emptying in mice. J Smooth Muscle Res. 2008;44(5):159-65.

25. Kinoshita K, Horiguchi K, Fujisawa M, Kobirumaki F, Yamato S, Hori $\mathrm{M}$, et al. Possible involvement of muscularis resident macrophages in impairment of interstitial cells of Cajal and myenteric nerve systems in rat models of TNBS-induced colitis. Histochem Cell Biol. 2007;127(1):41-53.

26. Hori M, Kita M, Torihashi S, Miyamoto S, Won KJ, Sato K, et al. Upregulation of iNOS by COX-2 in muscularis resident macrophage of rat intestine stimulated with LPS. Am J Physiol Gastrointest Liver Physiol. 2001;280(5):G930-8.

27. Sheibani K, Lucas FV, Tubbs RR, Savage RA, Hoeltge GA. Alternate chromogens as substitutes for benzidine for myeloperoxidase cytochemistry. Am J Clin Pathol. 1981;75(3):367-70.

28. Krawisz JE, Sharon P, Stenson WF. Quantitative assay for acute intestinal inflammation based on myeloperoxidase activity. Assessment of inflammation in rat and hamster models. Gastroenterology. 1984;87(6):1344-50.

29. Kono T, Omiya Y, Hira Y, Kaneko A, Chiba S, Suzuki T, et al. Daikenchuto (TU-100) ameliorates colon microvascular dysfunction via endogenous adrenomedullin in Crohn's disease rat model. J Gastroenterol. 2011;46(10):1187-96.

30. Hori M, Nobe H, Horiguchi K, Ozaki H. MCP-1 targeting inhibits muscularis macrophage recruitment and intestinal smooth muscle dysfunction in colonic inflammation. Am J Physiol Cell Physiol. 2008;294(2):C391-401.

31. Mikkelsen HB, Thuneberg L, Rumessen JJ, Thorball N. Macrophage-like cells in the muscularis externa of mouse small intestine. Anat Rec. 1985;213(1):77-86.

32. Schmidt J, Stoffels B, Chanthaphavong RS, Buchholz BM, Nakao A, Bauer AJ. Differential molecular and cellular immune mechanisms of postoperative and LPS-induced ileus in mice and rats. Cytokine. 2012;59(1):49-58.

33. Nagano T, Itoh H, Takeyama M. Effect of Dai-kenchu-to on levels of 3 brain-gut peptides (motilin, gastrin and somatostatin) in human plasma. Biol Pharm Bull. 1999;22(10):1131-3.

34. Jin XL, Shibata C, Naito H, Ueno T, Funayama Y, Fukushima K, et al. Intraduodenal and intrajejunal administration of the herbal medicine, dai-kenchu-tou, stimulates small intestinal motility via cholinergic receptors in conscious dogs. Dig Dis Sci. 2001;46(6):1171-6.

35. Sato $\mathrm{Y}$, Katagiri $\mathrm{F}$, Inoue $\mathrm{S}$, Itoh $\mathrm{H}$, Takeyama M. Dai-kenchu-to raises levels of calcitonin gene-related peptide and substance $\mathrm{P}$ in human plasma. Biol Pharm Bull. 2004;27(11):1875-7.

36. Satoh K, Hashimoto K, Hayakawa T, Ishige A, Kaneko M, Ogihara $\mathrm{S}$, et al. Mechanism of atropine-resistant contraction induced by Dai-kenchu-to in guinea pig ileum. Jpn J Pharmacol. 2001;86(1):32-7.

37. Tokita Y, Yamamoto $M$, Satoh K, Nishiyama M, Iizuka S, Imamura $\mathrm{S}$, et al. Possible involvement of the transient receptor potential vanilloid type 1 channel in postoperative adhesive obstruction and its prevention by a kampo (traditional Japanese) medicine, daikenchuto. J Pharmacol Sci. 2010;115(1):75-83.

38. Hayakawa T, Kase Y, Saito K, Hashimoto K, Ishige A, Komatsu Y, et al. Effects of Dai-kenchu-to on intestinal obstruction following laparotomy. J Smooth Muscle Res. 1999;35(2):47-54.

39. Angerson WJ, Allison MC, Baxter JN, Russell RI. Neoterminal ileal blood flow after ileocolonic resection for Crohn's disease. Gut. 1993;34(11):1531-4.

40. Kiyosue M, Fujisawa M, Kinoshita K, Hori M, Ozaki H. Different susceptibilities of spontaneous rhythmicity and myogenic contractility to intestinal muscularis inflammation in the hapteninduced colitis. Neurogastroenterol Motil. 2006;18(11):1019-30.

41. Kono T, Kaneko A, Hira Y, Suzuki T, Chisato N, Ohtake N, et al. Anti-colitis and -adhesion effects of daikenchuto via endogenous adrenomedullin enhancement in Crohn's disease mouse model. J Crohns Colitis. 2010;4(2):161-70.

42. de Jonge WJ, van der Zanden EP, The FO, Bijlsma MF, van Westerloo DJ, Bennink RJ, et al. Stimulation of the vagus nerve attenuates macrophage activation by activating the Jak2-STAT3 signaling pathway. Nat Immunol. 2005;6(8):844-51. 
43. The FO, Boeckxstaens GE, Snoek SA, Cash JL, Bennink R, Larosa GJ, et al. Activation of the cholinergic anti-inflammatory pathway ameliorates postoperative ileus in mice. Gastroenterology. 2007;133(4):1219-28.

44. van der Zanden EP, Snoek SA, Heinsbroek SE, Stanisor OI, Verseijden C, Boeckxstaens GE, et al. Vagus nerve activity augments intestinal macrophage phagocytosis via nicotinic acetylcholine receptor alpha4beta2. Gastroenterology. 2009;137(3): 102939, 39 e1-4.

45. Whiteaker P, Marks MJ, Christensen S, Dowell C, Collins AC, McIntosh JM. Synthesis and characterization of 125I-alphaconotoxin ArIB[V11L;V16A], a selective alpha7 nicotinic acetylcholine receptor antagonist. J Pharmacol Exp Ther. 2008;325(3):910-9. 